\title{
Dramatic Verrucae Confined to the Lower Lip
}

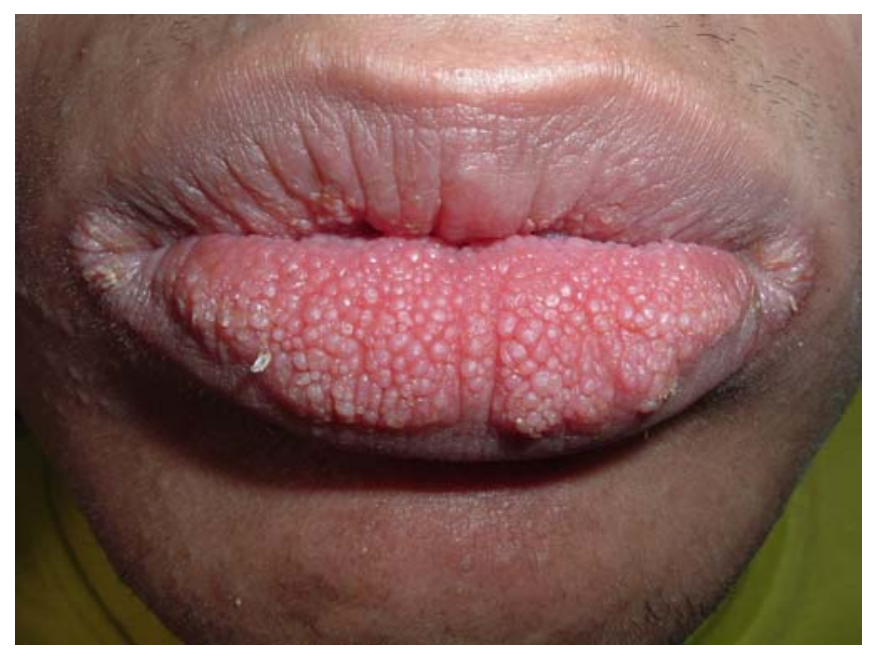

FIGURE. PCR for Human Papilloma Virus was not available.

\author{
M.R. Namazi ${ }^{1,2, \star}$ and J.L. Jorizzo ${ }^{1}$ \\ ${ }^{1}$ Dermatology Department, Wake Forest University Health Sciences, Winston- \\ Salem, North Carolina; ${ }^{2}$ Shiraz University of Medical Sciences, Shiraz, Iran \\ E-mail: namazi_mr@yahoo.com
}

Received February 19, 2008; Accepted April 24, 2008; Published May 1, 2008

\section{KEYWORDS: HPV, Wart, Verrucae}

A 16-year-old boy presented with a 3-year history of development of small papules on his lower lip. Histologic study of a biopsy specimen confirmed that the lesions were verrucae vulgaris. Other than having several genital warts, the patient was otherwise healthy and his HIV serology and full blood count were within normal limits.

The incubation period for common warts is 1-6 months. The causative virus most easily enters the body through an area of skin that is moist, peeling, or cracked. These lip lesions are particularly dramatic and unusual.

This article should be cited as follows:

Namazi, M.R. and Jorizzo, J.L. (2008) Dramatic verrucae confined to the lower lip. TheScientificWorldJOURNAL 8, 507. DOI 10.1100/tsw.2008.77. 


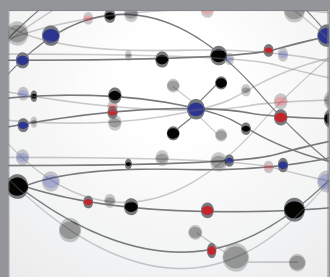

The Scientific World Journal
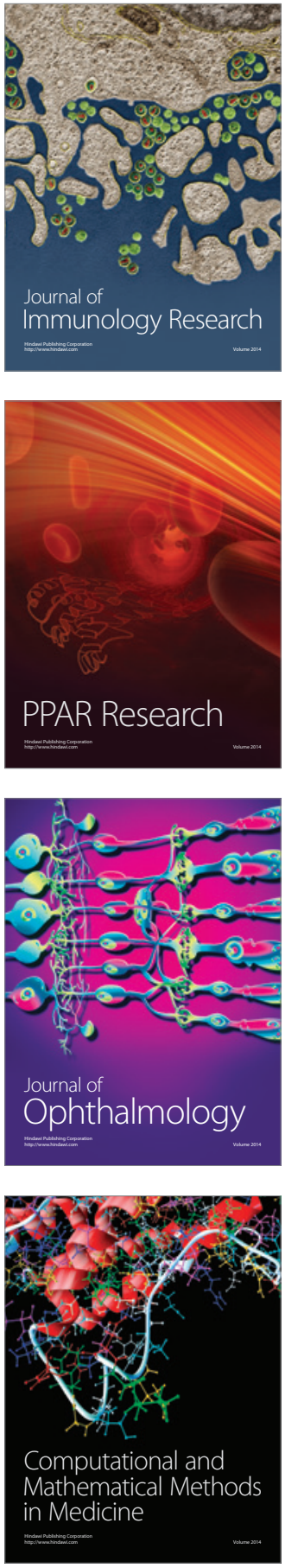

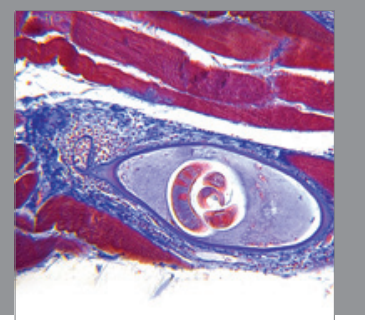

Gastroenterology

Research and Practice
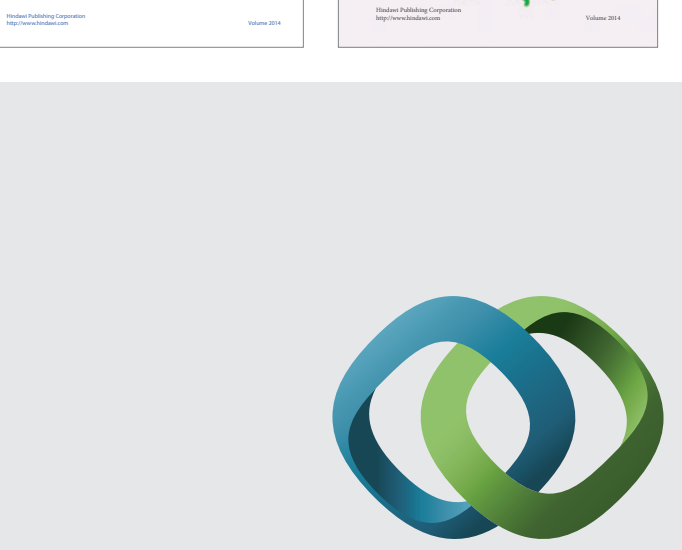

\section{Hindawi}

Submit your manuscripts at

http://www.hindawi.com
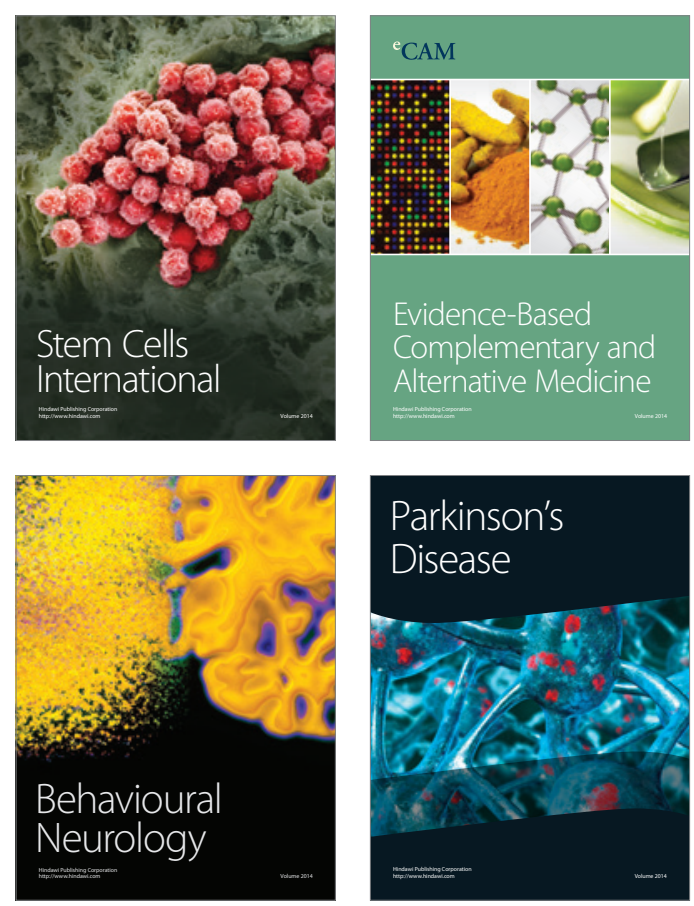

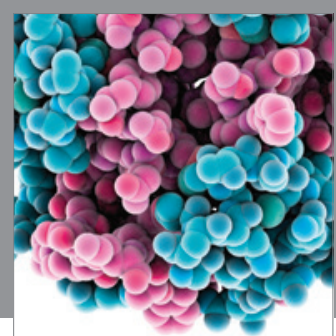

Journal of
Diabetes Research

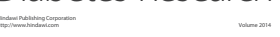

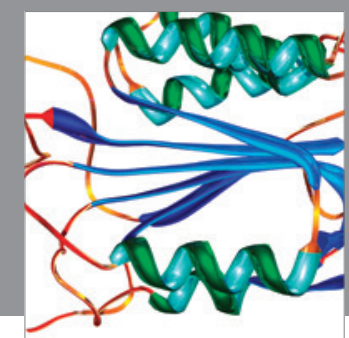

Disease Markers
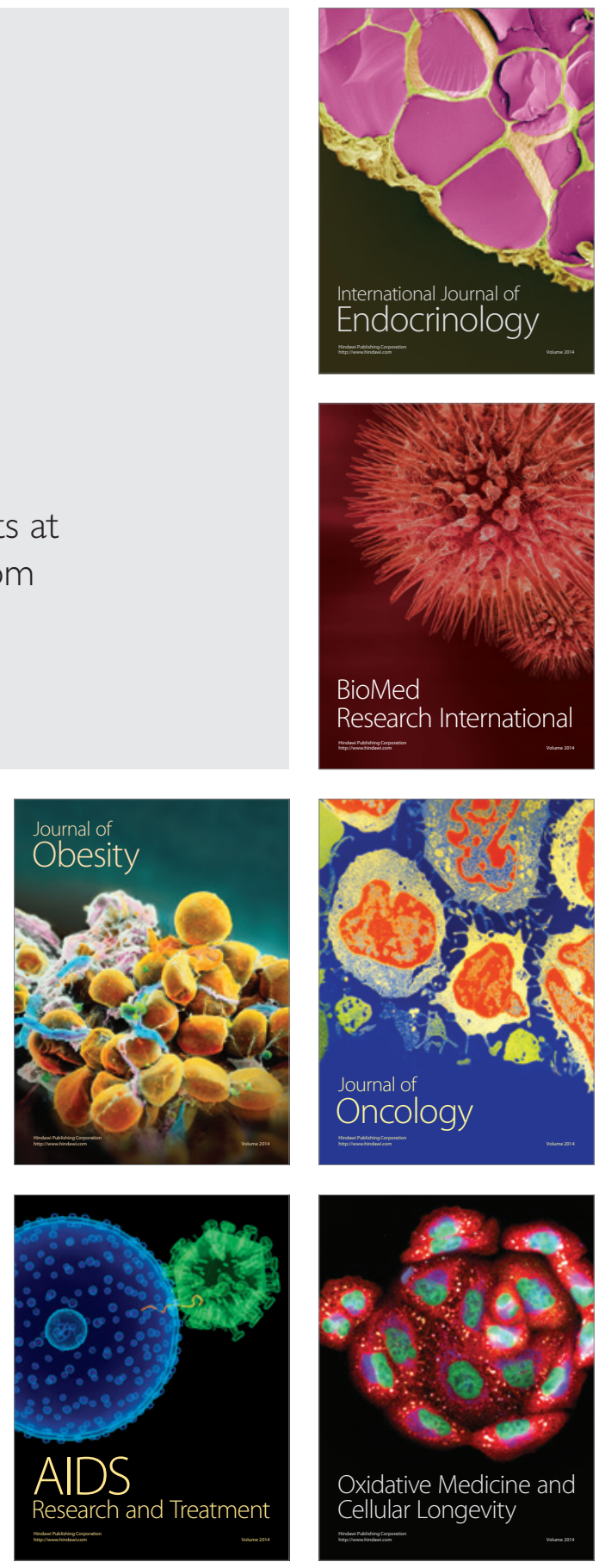